\title{
A Rarely Encountered Complication due to the Use of Warfarin: Spontaneous Intramural Hematoma in Jejunum: Two Case Reports
}

\author{
Husniye Baser ${ }^{\mathrm{a}, \mathrm{c}}$, Korhan Kollua, Yavuz Sultan Selim Akgul, \\ Salih Baser ${ }^{\mathrm{a}}$, Murat Serhat Aygun ${ }^{\mathrm{b}}$, Samil Ecirli ${ }^{\mathrm{a}}$
}

\begin{abstract}
Spontaneous intramural small bowel hematoma due to the overuse of warfarin is a rarely encountered complication. In most patients, hematoma may be ameliorated with conservative modalities, and surgery is rarely needed. We presented two cases here. The first, a 81-year-old male patient, was admitted to our clinic with the complaint of abdominal pain and on the use of warfarin $(5 \mathrm{mg} /$ day $)$ due to cerebrovascular event, congestive heart failure and atrial fibrillation. The physical examination revealed tenderness on abdominal left upper and lower quadrants. Prothrombin time, activated partial thromboplastin time and international normalized ratio were too long to measure clotting. On abdominal computerized tomography of the patient presenting with intestinal wall thickness on ultrasonography, wall thickness suggesting intramural hematoma was seen. Warfarin was discontinued, and fresh frozen plasma, erythrocyte suspension and intravenous fluids were given. During the follow-up, prothrombin time and international normalized ratio decreased to 14.6 seconds and 1.3 , respectively, and hematoma was found to reduced on abdominal US. The second case, a 76-year-old woman patient and on the use of warfarin $(5 \mathrm{mg} /$ day $)$, was admitted to the clinic with the complaints of abdominal pain, nausea and vomiting. She indicated common tenderness on abdominal examination, and activated partial thromboplastin time, prothrombin time and international normalized ratio were measured as $51.4 \mathrm{sec}$ onds, 43.9 seconds, and 3.8, respectively. Direct abdominal graphy showed no pathological finding. Abdominal ultrasonography and computerized tomography revealed wall thickness consistent with intramural hematoma on jejunum. Warfarin was discontunued, and fresh frozen plasma and intravenous fluids were administered. Activated partial thromboplastin time, prothrombin time and inter-
\end{abstract}

\footnotetext{
Manuscript accepted for publication July 5, 2013

${ }^{\mathrm{a} D e p a r t m e n t ~ o f ~ I n t e r n a l ~ M e d i c i n e, ~ K o n y a ~ E d u c a t i o n ~ a n d ~ R e s e a r c h ~}$ Hospital, Konya, Turkey

${ }^{\mathrm{b}}$ Department of Radiology, Konya Education and Research Hospital, Konya, Turkey

${ }^{\mathrm{c} C o r r e s p o n d i n g ~ a u t h o r: ~ H u s n i y e ~ B a s e r, ~ K o n y a ~ E d u c a t i o n ~ a n d ~ R e s e a r c h ~}$ Hospital, Department of Internal Medicine, Meram/Konya, Turkey.

Email: drhusniyebaser@yahoo.com.tr

doi: http://dx.doi.org/10.4021/jmc1377w
}

national normalized ratio were respectively decresed to $33.7 \mathrm{sec}-$ onds, 20.1 seconds, and 1.7. Spontaneous intramural small bowel hematoma is a serious complication, so early diagnosis and prompt medical treatment are important. Many patients may be treated with conservative modalities successfully.

Keywords: Warfarin; Spontaneous intramural hematoma; Jejunum

\section{Introduction}

Although intramural small bowel hematoma is a commonly encountered complication of blunt traumas, spontaneous intramural small bowel hematoma (SISBH) is a rarely encountered condition. In contrast to traumatic small bowel hematoma, mainly affecting duodenum and tending to involve short intestinal segment, SISBH is more extensive and commonly involves jejunum, followed by ileum and duodenum [1]. Through gastrointestinal tract, jejunum is the most affected part in up to $70 \%$ of such cases $[2,3]$. The most common cause of SISBH is known to be over-anticoagulation with vitamin $\mathrm{K}$ antagonists [4]. Patients with SISBH are generally admitted into clinics with the complaints of nausea, vomiting, crampy abdominal pain and often some degree of gastrointestinal bleeding, and the diagnosis can frequently be performed via radiological tests.

\section{Case Report}

\section{Case 1}

A 81-year-old male patient was admitted to our clinic with the complaints of abdominal pain and bruising on different parts of the body. With no history of traumas, the patient was determined to have experienced congestive heart failure, atrial fibrillation and ischemic cerebrovascular events twice 3 and 10 years earlier, and so had been on use of warfarin 5 $\mathrm{mg}$ /day. On physical examination, blood pressure and temperature were $130 / 70 \mathrm{mmHg}$ and $36.6^{\circ} \mathrm{C}$, respectively. Heart rate was detected to be $110 /$ minutes and arrhythmic. Several ecchymoses, the largest in size of $15 \mathrm{~cm}$ in diameter, 


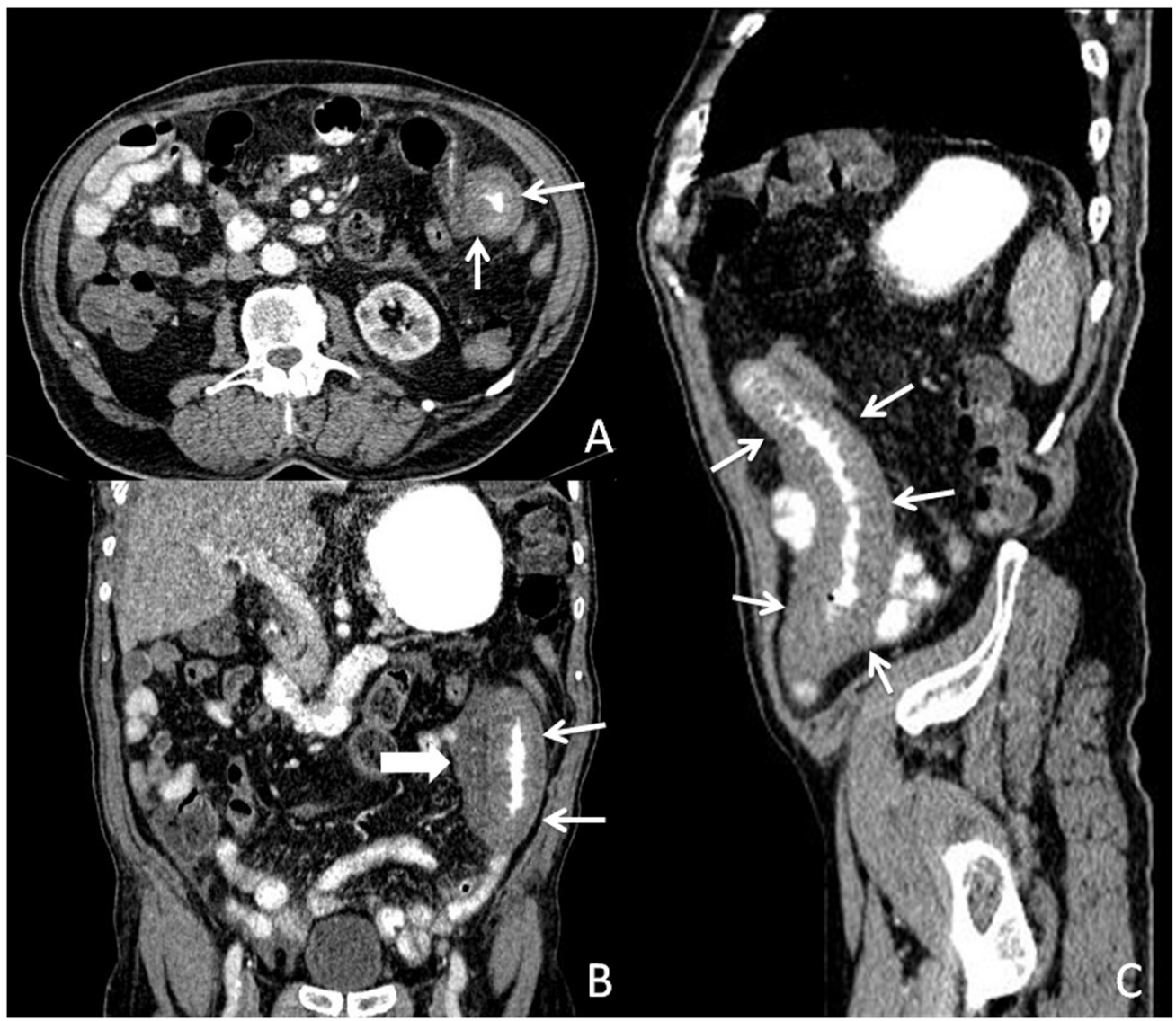

Figure 1. Post-contrast computed tomography image; (A) Axial plan, (B) Coronal plane, and (C) Parasagittal plane. Thickened jejunal bowels (small arrows), and high density surrounding free fluid (thick arrow), suggesting hemorrhage.

were present on anterior chest wall and left upper extremity. Abdominal left upper and lower quadrants showed common tenderness. Laboratory findings revealed the following: hemoglobin (Hb), $11.2 \mathrm{~g} / \mathrm{dL}$; hemotocrit (Hct), 34.4\%; leukocyte, $8,760 / \mathrm{mm}^{3}$; and, platelet count, $239,000 / \mathrm{mm}^{3}$. Prothrombin time (PT), activated partial thromboplastin time (aPTT) and international normalized ratio (INR) were too long to measure clotting. On follow-up, $\mathrm{Hb}$ was decreased to $9.6 \mathrm{~g} / \mathrm{dL}$. No pathological finding was detected on direct abdominal radiography. On abdominal ultrasonography (US) of the left lower and upper quadrants, a definite intestinal wall thickness was observed in a long segment. On computed tomography (CT) of the abdomen, a circumferential diffused wall thickening was detected, reaching $15 \mathrm{~mm}$ in the thickest site at distal jejunum (Fig. 1). So, warfarin was discontinued, and six units of fresh frozen plasma (FFP), one unit of erythrocyte suspension (ES) and intravenous fluids were given. Also, nasogastric suction was performed. Then, PT, aPTT, INR, Hb and Hct values were measured as 36.6 seconds (normal range 9.8 - 14.3 seconds), 42.7 seconds (normal range $20-36 \mathrm{sec}$ ), 3.3, $11.1 \mathrm{~g} / \mathrm{dL}$ and $34 \%$, respectively. On abdominal US performed on day 7 after the hospitalization, intestinal wall thickness was seen to be decreased to $4 \mathrm{~mm}$, and PT and INR values were found to decrease to 14.6 seconds and 1.3.

\section{Case 2}

A 76-year-old woman on the use of warfarin $(5 \mathrm{mg} /$ day) due to atrial fibrillation was admitted to the clinic with the complaints of abdominal pain, nausea and vomiting. She displayed no history of trauma. On physical examination, vital findings were stable, pulse rate was 96/minute and arrhythmic, and common tendernes was detected in abdomen. Laboratory findings were as follows: aPTT, 51.4 seconds; PT, 43.9 seconds; INR, 3.8; Hb, 9.2 gr/dL; Hct, 27.8\%; leukocyte, $6,810 / \mathrm{mm}^{3}$; and, platelet count, $192,000 / \mathrm{mm}^{3}$. On direct abdominal graphy, no finding suggesting intestinal obstruction was observed. On abdominal US, wall thickness was detected in intestinal segment in pelvic area. On abdominal $\mathrm{CT}$, diffused wall thickness consistent with intramural hematoma reaching $5 \mathrm{~mm}$ was observed in a segment of 9 $\mathrm{cm}$ in jejunum (Fig. 2), and warfarin was discontinued. Oral feeding was ceased. Intravenous fluids and three units of FFP were given, and so aPTT, PT and INR were decreased to 33.7 seconds, 20.1 seconds and 1.7, respectively. On abdominal 


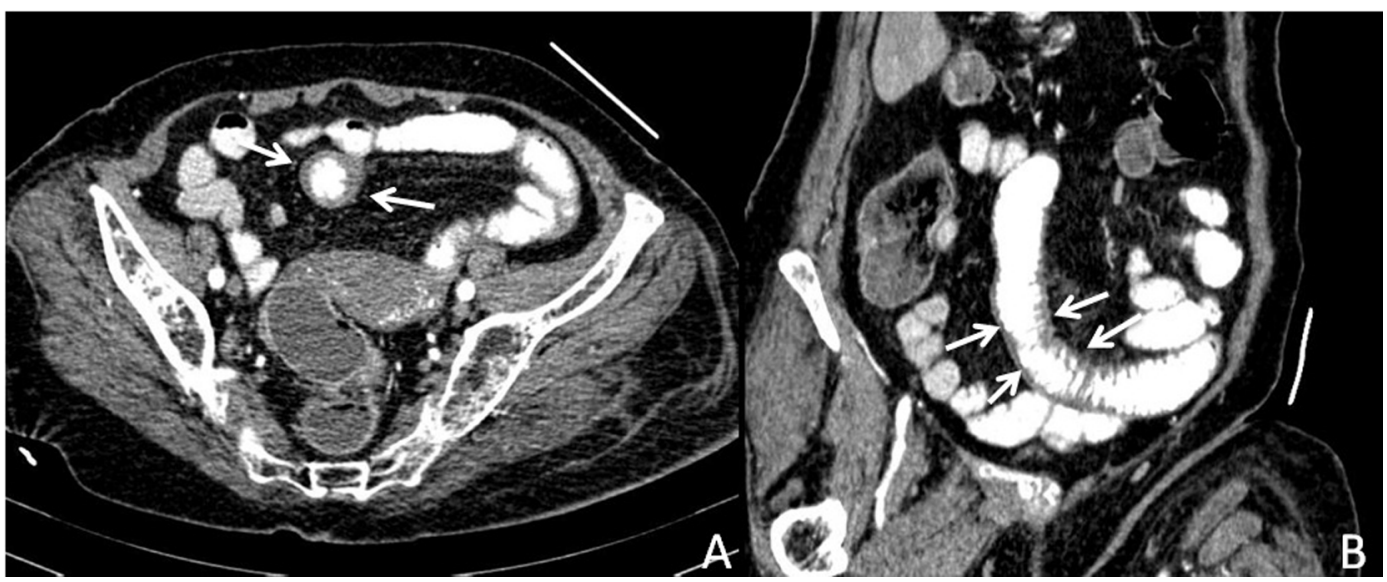

Figure 2. Post-contrast computed tomography image; (A) Axial plan, (B) Parasagittal plane. Thickened jejunal walls (arrows) suggesting intramural hematoma.

US performed on day 8 after hospitalization, no wall thickness was observed in intestinal segment.

\section{Discussion}

Oral anticoagulants are among drugs widely used in the treatment of many disorders, such as pulmonary embolism, deep vein thrombosis, prosthetic heart valves and persistent atrial fibrillation $[5,6]$. SISBH is an uncommon complication of anticoagulations. In literature, the frequency of spontaneous intramural hematoma is reported to take place in 1 per 2500 patients treated with anticoagulants [7].

SISBH is asserted to be a complication of bleeding disorders, malignancies and vasculitis, as well as excessive anticoagulants [3]. Along with factors mentioned above, endoscopic biopsies and injection therapy were also reported among other causes of intramural hematoma. However, as a very rare complication of endoscopic procedures, iatrogenic intramural duodenal hematoma is mainly observed in patients with coagulation or hematological disorders [8].

As a result of large spectrum, clinical presentation can range from mild, vague abdominal pain to intestinal obstruction and acute pain of abdomen. Nausea and vomiting are observed in approximately half of the cases and related to high intestinal obstruction including duodenum and proximal jejunum. Patients may also exhibit gastrointestinal hemorrhage due to ruptured hematoma [9]. While our case 1 was admitted just with the complaint of abdominal pain, case 2 was admitted with the complaints of nausea and vomiting, as well as abdominal pain.

Plain abdominal radiography is seldom specific and may be insufficient in demostrating the evidence of intestinal obstruction. The sonographic appearance of acute intramural small bowel hematoma is composed of a thickened intestinal wall, mainly involving the submucosal layer. However, such an abnormality is not specific for intestinal tract hematomas and can be witnessed in numerous disorders $[1,10]$. $\mathrm{CT}$ is the key modality in order to diagnose the condition. Among characteristic findings on CT are circumferential wall thickening, intramural hyperdensity, luminal narrowing and intestinal obstruction [3, 11]. The exact pathology can be achieved in all patients via the combination of CT and US [12]. Magnetic resonance imaging (MRI) characteristics of duodenal hematoma include well-defined concentric ring with a high signal intensity (ring sign). The unique MRI tissue characteristics (ring with short T1 and long T2 relaxation times) can be attributed to the paramagnetic properties of iron species within the hematoma [13]. Deep small bowel lesions can be determined using pull and push enteroscopy [14]. On both abdominal US and CT in our both cases, wall thickness was observed, and no additional procedures were considered to diagnose.

The best modalities to take up the treatment are to discontinue anticoagulant drugs, bowel rest, correction of PT with intravenous vitamin $\mathrm{K}$ and FFP, and correction of anemia, if present $[15,16]$. As a result of conservative treatment, an improvement of symptoms is usually seen within $4-6$ days. Complete amelioration is usually observed in almost all cases under conservative measures within 2 months after the onset $[17,18]$. When it comes to significant intramural hemorrhage, bowel perforation, ischemia or peritonitis, surgery is considered an only thereupatic option $[16,19]$. Continuing the anticoagulation therapy appears to be safe after the resolution of hematoma [20]. No anticoagulant treatment was commenced for cases 1 and 2, and both were discharged with the treatment of antiagregant.

SISBH was determined to develop in jejunum in our cases due to the use of warfarin, and the diagnosis was carried out via $\mathrm{CT}$ and US. Thanks to conservative treatment, hematoma was seen to decrease. So, the subjects were considered not to be required surgery. 
Both of the cases presented here were at older age, and SISBH, a serious complication due to the use of warfarin had developed. In light of both cases, it is considered that the decision for starting warfarin treatment meticulously be questioned, especially in the elderly and those for whom INR follow-up is too difficult.

\section{Conflict of Interest}

None declared.

\section{References}

1. Altikaya N, Parlakgumus A, Demir S, Alkan O, Yildirim T. Small bowel obstruction caused by intramural hematoma secondary to warfarin therapy: a report of two cases. Turk J Gastroenterol. 2011;22(2):199-202.

2. Sorbello MP, Utiyama EM, Parreira JG, Birolini D, Rasslan S. Spontaneous intramural small bowel hematoma induced by anticoagulant therapy: review and case report. Clinics (Sao Paulo). 2007;62(6):785-790.

3. Abbas MA, Collins JM, Olden KW. Spontaneous intramural small-bowel hematoma: imaging findings and outcome. AJR Am J Roentgenol. 2002;179(6):13891394.

4. Abdel Samie A, Theilmann L. Detection and management of spontaneous intramural small bowel hematoma secondary to anticoagulant therapy. Expert Rev Gastroenterol Hepatol. 2012;6(5):553-558; quiz 559.

5. Hirsh J. Oral anticoagulant drugs. N Engl J Med. 1991;324(26): 1865-1875.

6. Palareti G, Leali N, Coccheri S, Poggi M, Manotti C, D'Angelo A, Pengo V, et al. Bleeding complications of oral anticoagulant treatment: an inception-cohort, prospective collaborative study (ISCOAT). Italian Study on Complications of Oral Anticoagulant Therapy. Lancet. 1996;348(9025):423-428.

7. Bettler S, Montani S, Bachmann F. [Incidence of intramural digestive system hematoma in anticoagulation. Epidemiologic study and clinical aspects of 59 cases observed in Switzerland (1970-1975)]. Schweiz Med Wochenschr. 1983;113(17):630-636.

8. Sugai K, Kajiwara E, Mochizuki Y, Noma E, Nakashima J, Uchimura K, Sadoshima S. Intramural duodenal hematoma after endoscopic therapy for a bleeding duo- denal ulcer in a patient with liver cirrhosis. Intern Med. 2005;44(9):954-957.

9. Veldt BJ, Haringsma J, Florijn KW, Kuipers EJ. Coumarin-induced intramural hematoma of the duodenum: case report and review of the literature. Scand J Gastroenterol. 2011;46(3):376-379.

10. Rauh P, Uhle C, Ensberg D, Rickes S, Monkemuller K, Fry L, Malfertheiner P. Sonographic characteristics of intramural bowel hematoma. J Clin Ultrasound. 2008;36(6):367-368.

11. Cheng J, Vemula N, Gendler S. Small bowel obstruction caused by intramural hemorrhage secondary to anticoagulant therapy. Acta Gastroenterol Belg. 2008;71(3):342344.

12. Polat C, Dervisoglu A, Guven H, Kaya E, Malazgirt Z, Danaci M, Ozkan K. Anticoagulant-induced intramural intestinal hematoma. Am J Emerg Med. 2003;21(3):208211.

13. Abdel Samie A, Sun R, Theilmann L. A rare cause of obstructive jaundice. Gastroenterology. 2009;137(1):40, 394.

14. Shinozaki S, Yamamoto H, Kita H, Yano T, Miyata T, Sunada K, Sekine Y, et al. Direct observation with double-balloon enteroscopy of an intestinal intramural hematoma resulting in anticoagulant ileus. Dig Dis Sci. 2004;49(6):902-905.

15. Abbas MA, Collins JM, Olden KW, Kelly KA. Spontaneous intramural small-bowel hematoma: clinical presentation and long-term outcome. Arch Surg. 2002;137(3):306-310.

16. Jones WR, Hardin WJ, Davis JT, Hardy JD. Intramural hematoma of the duodenum: a review of the literature and case report. Ann Surg. 1971;173(4):534-544.

17. Carkman S, Ozben V, Saribeyoglu K, Somuncu E, Erguney S, Korman U, Pekmezci S. Spontaneous intramural hematoma of the small intestine. Ulus Travma Acil Cerrahi Derg. 2010;16(2):165-169.

18. Ashley S. Spontaneous mesenteric haematoma and small bowel infarction complicating oral anticoagulant therapy. J R Soc Med. 1990;83(2):116.

19. Eiland M, Han SY, Hicks GM, Jr. Intramural hemorrhage of the small intestine. JAMA. 1978;239(2):139142 .

20. Hou SW, Chen CC, Chen KC, Ko SY, Wong CS, Chong CF. Sonographic diagnosis of spontaneous intramural small bowel hematoma in a case of warfarin overdose. $\mathrm{J}$ Clin Ultrasound. 2008;36(6):374-376. 